American Journal of Pharmaceutical Education 2019; 83 (8) Article 6967.

\title{
RESEARCH
}

\section{An Elective Course in Lesbian, Gay, Bisexual, and Transgender Health and Practice Issues}

\author{
Michael W. Jann, PharmD, ${ }^{\text {a }}$ Scott Penzak, PharmD, ${ }^{\mathrm{b}}$ Annesha White, PharmD, PhD, ${ }^{\mathrm{a}}$ \\ Amulya Tatachar, PharmD ${ }^{\mathrm{a}}$ \\ ${ }^{\text {a }}$ University of North Texas System College of Pharmacy, Fort Worth, Texas \\ ${ }^{\mathrm{b}}$ Auburn University Harrison School of Pharmacy, Auburn, Alabama \\ Submitted January 22, 2018; accepted January 29, 2019; published October 2019.
}

\begin{abstract}
Objective. To design, implement and assess a lesbian, gay, bisexual, and transgender (LGBT) health and practice elective course for second- and third-year Doctor of Pharmacy (PharmD) students.

Methods. The course focused on health promotion, health care barriers, disease prevention, and treatment throughout an LGBT person's lifespan. The course included topic discussions, reading assignments, various active-learning activities, an objective structured clinical examination (OSCE) with a transgender person, and guest speakers from the LGBT community. Five quizzes were administered during the course that were mapped to specific session learning objectives and course learning outcomes. Students completed an anonymous pre- and post-course survey on the seven course learning outcomes to assess their knowledge and skills regarding the health of LGBT people.

Results. Students exhibited significant learning with improvement in the seven course learning outcomes. The two most improved course learning outcomes were the medications used for LGBT people and summarizing health care resources available to LGBT people. The content of student portfolios included general themes of discrimination, health care access problems, advocacy, inclusive pharmacy environments, and desire to be a better practitioner. More than $91 \%$ of the students actively engaged the guest speakers from the LGBT community. Student performance on quizzes and in the OSCE activity was excellent. The capstone presentations covered a variety of topics including LGBT in Islam.

Conclusion. Students demonstrated knowledge of the unique health care issues among the LGBT community. This elective course provides a framework for other pharmacy programs to incorporate LGBT health topics into the curriculum and to engage with their local LGBT community.
\end{abstract}

Keywords: lesbian, gay, bisexual, transgender, queer

\section{INTRODUCTION}

The health care of lesbian, gay, bisexual, and transgender (LGBT) persons has been incorporated into the Healthy People 2020 goals and objectives, which state that these people have significant barriers to health care because of societal stigma, discrimination, and denial of their civil rights. ${ }^{1}$ Based on limited data, an estimated $3.4 \%$ of the US population identifies as lesbian, gay, or bisexual. $^{2}$ In 2010, approximately 950,000 persons identified as transgender individuals. ${ }^{3,4}$ The percentage of women and men aged 18 to 29 years identified as LGBT individuals was $8.3 \%$ and $4.6 \%$, respectively. ${ }^{5}$ However, as the age demographic increased, the percentages of per-

Corresponding Author: Michael W. Jann, University of North Texas System College of Pharmacy (UNTSCP), University of North Texas Health Science Center (UNTHSC), 3500 Camp Bowie Blvd., Ft. Worth, TX 76107. Tel: 817-7352620. Fax: 817-735-2683. E-mail: Michael.jann@unthsc.edu sons identifying as LGBT decreased from 3.2\% (ages 3049 years) to $1.6 \%$ (65+ years). Correspondingly, as the age demographic increased, the percentage of persons refusing to answer or choosing "don't know" increased from $3.2 \%$ (30-49 years) to $6.5 \%$ (65+ years). According to the 2010 US Census same-sex households are present in $93 \%$ of all US counties. ${ }^{6}$

The Healthy People 2020 document describes a shortage of health care providers who are culturally competent in LGBT health. ${ }^{1}$ A survey sent to the deans of medical school programs in Canada and the United States $(\mathrm{N}=150)$ indicated that the median time spent on LGBT-related topics in the curriculum was five hours (range three to eight hours), and faculty development for teaching these topics was offered in only 27 programs. ${ }^{7}$ Of the 4,262 medical students surveyed, $67 \%$ agreed that the curricula containing specific LGBT areas could be improved, and they felt comfortable with but not fully prepared to care for 


\section{American Journal of Pharmaceutical Education 2019; 83 (8) Article 6967.}

LGBT patients. ${ }^{8}$ A survey of physician assistant programs $(\mathrm{N}=106)$ reported a median time of 12 hours in the curriculum dedicated to general sexual health topics. ${ }^{9}$ A 2015 survey in which students from 69 out of 138 medical school programs responded revealed that only $16 \%$ of the programs included competency-based training in LGBT health. Thirty-two percent of the medical schools had LBGT-related components in their training programs, while $52 \%$ lacked any training. ${ }^{10}$ An elective interprofessional LGBT Queer, Intersex (QI) health forum to supplement the health care curricula was developed that included medical, pharmacy, nursing, dentistry, and physical therapy students that consisted of 10 hours of content presented over a weekend. ${ }^{11}$ Few physicians self-identify as competent in LGBT health care and practice. ${ }^{12}$ Despite efforts like these, another study of US physicians found that only $16 \%$ reported having LBGT-competency training. ${ }^{13}$ For the few programs that incorporate training in LGBT health, most include it under an "umbrella" term that lacks differentiation between these groups and ignores the unique health issues of each. This occurs despite the availability of published guidelines to aid training programs in standardizing education for health care professionals. ${ }^{13-15}$

As integral members of the health care team, it is essential for pharmacists to be culturally competent. If not culturally competent, whether the pharmacist is a trusted professional can be questioned. ${ }^{16}$ The Accreditation Council for Pharmacy Education (ACPE) emphasizes the significance of cultural competency in the standards used for pharmacy program assessment. Standards 3 and 4 provide only guidance related to the importance of cultural competency. Specific statements on LGBT health issues are not mentioned. ${ }^{17}$ The American Association of Colleges of Pharmacy (AACP) has sponsored an institute entitled, "Cultural Competency: Beyond Race and Gender," where they noted that LGBT issues were underappreciated and then provided selected resources for instruction. ${ }^{18} \mathrm{~A}$ cultural competency course was described for selected sociocultural groups but lacks LGBT persons as a specific entity. ${ }^{19}$ Although LGBT health-related issues may be sparsely incorporated into various courses such as these, pharmacy programs that have a dedicated course on the topic are rare. ${ }^{20,21}$ For example, a two-hour didactic lecture on transgender health care was included in a therapeutics course on special populations, and a panel discussion on transgender health care was incorporated into a required diversity course, which was favorably received by the students and engaged the transgender community. ${ }^{20,22}$ Many challenges for the health care of LGBT persons exist. The practice of pharmacy and educational programs must continue to evolve to meet the needs of these individuals. ${ }^{23}$
The specific goals of the elective course described here were to develop, implement, and assess pharmacy students' knowledge of and skills in managing the different health-related issues among LGBT persons. Assessment of the specific course learning outcomes supported by didactic discussion topics with quizzes, active-learning activities, an objective structured clinical examination (OSCE), and student portfolios were key elements to determine student achievement.

\section{METHODS}

Didactic topics for the course were chosen in a systematic manner using the course learning outcomes developed from guidelines regarding LGBT health issues. ${ }^{9,10}$ Additionally, faculty members reviewed publications on LGBT health and practice issues found through PubMed, established websites, and other literature resources to find ideas for didactic topics and activelearning strategies. Faculty members also consulted with LGBT academic organizations, such as the Fenway Institute, and with the Vanderbilt School of Medicine, which offers an LGBT elective course for medical students. Pharmacy faculty members discussed the elective course with UNT faculty leaders in other health sciences programs (medicine, physician's assistant, and public health) to obtain their input regarding discussion topics and on interprofessional (IPE) education. The final didactic topics and active-learning activities selected for the course are presented in Table 1.

Seven course learning outcomes were defined and derived from the selected didactic topics (Table 2). ${ }^{13-15}$ A pre- and post-course anonymous survey instrument was developed to assess learning outcomes (Table 2). To protect students' privacy and encourage more candid responses, each student selected a four-digit code that course faculty reviewed to ensure there were no duplicate numbers. Each student used the same four-digit code when submitting all survey assessments to ensure course completion. The pre-course survey was conducted at the beginning of the first-class session while the post-course survey was completed during the last class session. A key question on the pre-course survey was whether the student had had previous exposure to the LGBT community. Surveys were collected in a covered box kept at the front of the room. To ensure privacy, there was no faculty monitoring as students deposited their surveys at the end of the class session.

The quantitative and qualitative assessments developed to evaluate students' knowledge and comprehension of course learning outcomes (Table 2) included formal quizzes, active-learning strategies such as the OSCE activity, peer-review classroom participation, small group 


\section{American Journal of Pharmaceutical Education 2019; 83 (8) Article 6967.}

Table 1. Discussion Topics and Active-Learning Activities Included in an Elective Course for Pharmacy Students on LGBT Health and Practice

\begin{tabular}{ll}
\hline Discussion Topics & \multicolumn{1}{c}{ Active-Learning Activities } \\
\hline Overview of sex, sexuality and sexual health & Peer teaching \\
Components of and taking a sexual history & Learning and developmental self-reflection in the portfolio \\
LGBT health disparities & Small group journal club discussions by students \\
Disorders of sexual development & Discussions led by faculty and students \\
Lesbian health issues & Guest speakers from the LGBT community \\
Bisexual health issues & Modified case studies from the Fenway Guide ${ }^{13}$ \\
Transgender health issues & Engagement with LGBT community groups \\
Gender nonconformity and gender discordance & OSCE activity with transgender patients \\
Legal and ethical aspects of LGBT health & Capstone presentation \\
Interdisciplinary care for LGBT youth and older adults & \\
HIV prevention, screening, prep and outreach & \\
STD prevention and treatment & \\
Anal HPV and cancer & \\
Mental health care for LGBT persons & \\
Substance abuse among LGBT persons &
\end{tabular}

Abbreviations: LGBT=lesbian, gay, bisexual, transsexual

presentations of a capstone presentation, professionalism, student self-reflections for each topic discussion, ability to identify barriers to health care and resources, and student course evaluations. Five quizzes were administered during the course. Each quiz included sexual terminology definitions and three class topic sessions (Table 1). Quizzes consisted of 20 multiple-choice questions and were administered via the UNTHSC Canvas platform. Students had 30 minutes to complete each quiz. Each quiz included five questions on sexual terminology that tied to course learning outcome 1 . The remaining 15 questions were linked to a specific topic session learning objective, which was then linked to the remaining six course learning outcomes. For example, a quiz question on hormonal therapy for a transgender individual was linked to the session learning objective "Compare and contrast hormonal therapies for transgender persons," which then connected with course learning outcome 4 shown in Table 2. The total number of quiz questions for the course was 100 and each one was linked to one of the seven course learning

Table 2. Course Learning Outcomes of the Elective LGBT Health and Practice Pre and Post-Course Evaluation with Quiz and OSCE Assessment Results ( $\mathrm{N}=36)$

\begin{tabular}{|c|c|c|c|c|c|c|}
\hline Learning Outcome & $\begin{array}{l}\text { Pre-M } \\
(\text { SD })^{\mathbf{a}}\end{array}$ & $\begin{array}{l}\text { Pre- } \\
\text { SA/A } \\
(\%)^{\text {b }}\end{array}$ & $\begin{array}{c}\text { Post-M } \\
\text { (SD) }^{\mathbf{a}}\end{array}$ & $\begin{array}{l}\text { Post- } \\
\text { SA/A } \\
(\%)^{\text {b }}\end{array}$ & $\begin{array}{c}\text { Quiz (\%) M (SD) } \\
\text { OSCE Results } \\
\text { (\%) }\end{array}$ & $\begin{array}{l}\text { Quiz } \\
\text { Range } \\
\text { (\%) }\end{array}$ \\
\hline $\begin{array}{l}\text { 1. I can define the commonly used terms in LGBT } \\
\text { health such as gender identity }\end{array}$ & $3.8(0.80)$ & 74 & $5.0(0.17)$ & 100 & $\begin{array}{c}91.2(6.0) \\
100 \%\end{array}$ & $80.0-100$ \\
\hline $\begin{array}{l}\text { 2. I can describe methods for showing respect to LGBT } \\
\text { persons }\end{array}$ & $3.6(0.82)$ & 56 & $5.0(0.17)$ & 100 & $\begin{array}{l}92.4(7.2) \\
100 \%\end{array}$ & $86.7-100$ \\
\hline $\begin{array}{l}\text { 3. I can distinguish between the various health } \\
\text { conditions that differ between LGBT persons }\end{array}$ & $2.7(0.84)$ & 18 & $4.6(0.61)$ & 94 & $\begin{array}{l}93.3(4.2) \\
\text { N.A. }\end{array}$ & $86.4-100$ \\
\hline $\begin{array}{l}\text { 4. I can list the commonly used medication categories } \\
\text { used for LGBT persons }\end{array}$ & $2.1(0.79)$ & 3 & $4.5(0.17)$ & 91 & $\begin{array}{c}82.2(6.4) \\
72 \%\end{array}$ & $70.3-92.6$ \\
\hline $\begin{array}{l}\text { 5. I can summarize the health care resources available } \\
\text { to LGBT persons }\end{array}$ & $2.1(0.91)$ & 3 & $4.6(0.66)$ & 97 & $\begin{array}{l}91.2(8.4) \\
100 \%\end{array}$ & $83.3-100$ \\
\hline 6. I can identify barriers to treatment for LGBT persons & $3.0(0.98)$ & 21 & $5.0(0.17)$ & 100 & $89.2(4.4)$ & $87.5-100$ \\
\hline $\begin{array}{l}\text { 7. I can develop strategies for advocacy for the health } \\
\text { care needs for LGBT persons }\end{array}$ & $2.9(1.0)$ & 29 & $4.9(0.29)$ & 100 & $\begin{array}{c}100 \% \\
92.8(9.7) \\
100 \%\end{array}$ & $80.0-100$ \\
\hline
\end{tabular}

${ }^{a}$ Mann-Whitney Wilcoxon Test, all items $p<.01$

${ }^{\mathrm{b}} \mathrm{SA} / \mathrm{A}$ Percent of students who chose strongly agree (5) or agree (4). Choices 1, 2, and 3 were strongly disagree, disagree and neutral, respectively $\mathrm{NA}=$ not applicable, $\mathrm{M}=$ mean, $\mathrm{SD}=$ standard deviation 


\section{American Journal of Pharmaceutical Education 2019; 83 (8) Article 6967.}

outcomes. The quiz results from each student and from each quiz question were tabulated and mapped to one of the seven course learning outcomes. The total number of correct quiz answers for each student for each course learning outcome was then determined from the quiz results.

The OSCE activity included a simulated patient counseling session where a two-person student team met with an actual transgender person with a prescription for either estradiol or depo-testosterone. The decision to have two-person student teams was made based upon the limited availability of transgender persons to participate in the class activity. In case of a single student, the one student volunteered to complete the OSCE individually. The two sample prescriptions were placed into the Canvas electronic platform two weeks prior to the scheduled OSCE class event. The students were randomly assigned to counsel either a trans-man or trans-woman and had 10 minutes to complete the session. A grading rubric was created, with nine items grouped into three categories: patient information; management strategies (including patient education); and monitoring with follow-up appointments. ${ }^{27}$ The patient information section contained three questions about the patient's concerns, name preference, and asked any challenges in their therapy and were linked to the Course Learning Outcomes displayed in Table 2. The management strategies section of the rubric consisted of four questions about the patient's explanation and education about medication adverse effects, medication adherence, and hormonal dose scheduling and also linked to The Course Learning Outcomes displayed in Table 2. The monitoring and follow-up section of the rubric included two questions regarding patient monitoring information, follow-up appointments, and a question-and-answer session incorporating a patient teach-back technique back to the students on the three sections. The transgender persons were trained by the faculty member on the grading rubric for accepted answers and completed grading the students with a simple yes/no if the students included the item (eg, explain adverse effects). Students received one point for completing the item and no points for not including the item during the simulated patient counseling session.

Guest speakers in the course included the physician director of the LGBT Clinic at University of Texas Southwestern/Parkland Health System, senior clergy from churches that consist of LGBT members, a psychotherapist specializing in LGBT health, and LGBT persons who shared their experiences with the health care system. Using a class session evaluation rubric (Table 3), course faculty members observed each student during each session to assess class participation, ie, interaction with guest speakers, discussion of case study examples, and participation in journal club. The faculty member assigned a grade (\%) for each student for each session. The final student grade for class participation was based upon the total number of class sessions attended, the number of times the student participated in the classroom discussions, and the number of times the student led the class discussion. Each student was required to lead one case study, journal club, or topic discussion during the course as assigned by the course faculty. The total number of percentage points generated from each session was averaged and then multiplied by $14.2 \%$ for this section (Table 3 ). For example, if a student achieved a $95 \%$ average for class participation, multiplied by $14.2 \%$ would equal $13.5 \%$ the student's grade percentage points for class participation.

Students were required to write a one- to two-page self-reflection on their thoughts, feelings, evaluation, and analysis about each topic for each class session. Additionally, a self-reflection regarding any 10 news or internet items regarding LGBT health or policy issues were required. Self-reflections were evaluated by the faculty for the qualitative assessment based upon the Gibbs' Reflective Cycle. ${ }^{24}$ Students were free to write about any aspects of the session as long as the self-reflections contained original thoughts and summarized the session. All students were required to evaluate President Trump's policy regarding transgender persons in the military and provide updates on the issue during the course. Students were given specific instructions that their portfolios contain both learning and reflective statements. The learning section for all students included following the same public policy statement and its impact on the LGBT community. ${ }^{25}$ Using Creswell's methodology, ${ }^{26}$ the student self-reflections were reviewed by the course faculty members for themes and subthemes that involved "identifying significant statements, clustering themes, and an essential experience." The students' self-reflections were an integral aspect of their course portfolios.

The capstone presentation was conducted in small groups of two to three students and included an in-depth discussion on a selected topic that had been approved by the course faculty member. Each group presented a 15minute PowerPoint presentation on the topic. Faculty members used a rubric consisting of 10 items rated on a scale from one to five $(1=$ strongly disagree to $5=$ strongly agree) to evaluate the presentations. Three students were randomly selected to assess each group presentation, with all students participating in the grading. The total score was determined by combining the faculty and students' scores (50/50). Student professionalism in the course was also assessed. Student portfolios were evaluated based on 


\section{American Journal of Pharmaceutical Education 2019; 83 (8) Article 6967.}

Table 3. Class Participation Rubric Used to Evaluate Pharmacy Students Enrolled in an Elective Course on LGBT Health

\begin{tabular}{ll}
$\begin{array}{l}\text { Score, } \\
\%\end{array}$ & Statement in Rubric \\
\hline$<70$ & $\begin{array}{c}\text { Disrespectful of peers, faculty or LGBT guests, attendance problems }(<80 \%) \text {, or rarely participates in classroom } \\
\text { discussions } \\
71-80\end{array}$ \\
$\begin{array}{c}\text { Respectful of peers, faculty, or LGBT guests, participates in classroom discussions, but rarely takes a leadership role ( } \leq \\
20 \% \text { of total class time) } \\
81-90\end{array}$ & $\begin{array}{c}\text { Encouraging and respectful to peers, faculty, or LGBT guests, actively participates classroom discussions, and takes a } \\
\text { leadership role }(21-50 \%)\end{array}$ \\
$91-100$ & $\begin{array}{c}\text { Encouraging and respectful to peers, faculty, or LGBT guests, actively participates classroom discussions, and takes a } \\
\text { leadership role }(>51 \%)\end{array}$ \\
\hline
\end{tabular}

Abbreviations: LGBT=lesbian, gay, bisexual, transgender

completeness of each assigned topic, self-reflections, OSCE activity results, class participation, capstone project, and presentation. The final element in the student portfolio was a 1- to 2-page self-reflection summary of what the student had learned during the elective course.

The elective course was a graded course, and the largest portion of the grade (40\%) was based on the portfolios. The learning portfolio section of the student's portfolio required each student to independently analyze and provide subsequent self-reflective discussions on the Trump Administration's policy on transgender persons serving in the military. Student evaluation and assessment of course content and terminology occurred via five formative quizzes during the semester (total 16.6\%). Other assessments included student class participation (14.2\%), group capstone presentation (16.6\%), OSCE evaluation by the trans-person (6\%), and professionalism (6.6\%).

Student participation in the course evaluation was voluntary and anonymous. A course fee of $\$ 60$ per student was charged to support the guest speakers' time and efforts. Pre- and post-course analysis for the course learning outcomes was conducted using the unpaired Mann-Whit-
ney-Wilcoxon (MWW) test. Significance was defined as $p<.05$. Descriptive statistics were used for the student course evaluations presented in Table 4. Selection of the MWW versus the $t$ test for the analysis of the Likert data was based upon the skewness of the data's distribution as both tests have a similar power. ${ }^{28}$

No student identifying information was included in data collection. The UNTHSC Institutional Review Board reviewed and approved the study.

\section{RESULTS}

Thirty-six students completed the elective course offered in the 2017 spring (15 students) and fall (21 students) semesters. Of the 36 students, eight (22.2\%) were in their third-year of the PharmD program and 28 (77.8\%) were in their second year. Eleven male $(31 \%)$ and 25 female students $(69 \%)$ enrolled in the course. Students' ethnic backgrounds included Caucasian, 30\%; Asian, $30 \%$; African, 20\%; Hispanic, 15\%; and other, 5\%. Six students were of Middle Eastern descent. All students completed a pre- and post-course survey based upon the course learning outcomes as shown in Table 2. The

Table 4. Pharmacy Student Evaluations of an Elective Course on LGBT Health and Practice $(\mathrm{N}=19)^{\mathrm{a}}$

\begin{tabular}{l}
\hline Questions \\
\begin{tabular}{ll} 
1. The content (subject matter) was organized in a way that facilitated my learning & Mean (SD) $^{\mathbf{b}}$ \\
2. The instructional design encouraged student involvement and interaction & $4.5(0.66)$ \\
3. The stated goals and objectives of this course were met & $4.7(0.44)$ \\
4. This course used appropriate instructional technologies to enhance my learning experience & $4.5(0.66)$ \\
5. The examinations were representative of materials and objectives presented in the course & $4.4(0.51)$ \\
6. This course challenged me to think and learn & $4.5(0.44)$ \\
7. Attending course activities facilitated my learning & $4.7(0.63)$ \\
8. This course advanced my ability to analyze and critically evaluate ideas, materials, and/or concepts & $4.6(0.66)$ \\
9. This course demonstrated the integration of key concepts of basic biomedical science & $4.5(0.66)$ \\
10. Student involvement and interaction were encouraged in this course & $4.8(0.44)$ \\
11. The time allocated for this course was sufficient for me to learn and apply the assigned material & $4.6(0.65)$ \\
\hline
\end{tabular}
\end{tabular}

${ }^{a}$ Includes data from both spring and fall 2017 semesters

${ }^{\mathrm{b}}$ Items were rated using a 5 -point Likert scale on which $5=$ strongly agree, $4=$ agree, $3=$ neutral, $2=$ disagree, and $1=$ strongly disagree Abbreviations: LGBT=lesbian, gay, bisexual, transgender 


\section{American Journal of Pharmaceutical Education 2019; 83 (8) Article 6967.}

improvement in scores on the course learning outcomes from the pre-course to post-course was significant for each question $(p<.01)$. The two items with the most significant improvements were that students were able to identify and summarize the health care resources available to LGBT persons and discuss the medications prescribed for LGBT persons. The percentage of students who responded either strongly agree or agree dramatically increased from 3\% to over $90 \%$ for these two course learning outcomes. Other course learning outcomes that showed improvement were being able to distinguish between the various health conditions of LGBT persons, develop strategies for their advocacy, and identify barriers to the treatment of LGBT persons. The percentage of students who responded strongly agree or agree increased from less than $30 \%$ pre-course to greater than $94 \%$ post-course. On the pre-course survey, students responded strongly agree or agree on only two of the seven course learning outcomes; on the post-course survey, greater than $50 \%$ of the students responded strongly agree or agree. On the post-course survey, all students agreed with greater than $91 \%$ for the course learning outcomes, with four items achieving 100\%.

Five quizzes were used to assess students' achievement of the seven course learning outcomes. The mean scores and score range are reported in Table 2. The three course learning outcomes with the most quiz questions were 1,3 , and 4 . Course learning outcome 4 had the lowest mean score of $82.2 \%(\mathrm{SD}=6.4)$ with only three students achieving the highest of score $92.6 \%$. The number of students who had a mean quiz scores that ranged between $80 \%-89 \%$ and $70 \%-79 \%$ were 19 and 14 , respectively. Five course learning outcomes had mean quiz scores greater than $90 \%$ with only outcome 6 having a mean of $89.2 \%(\mathrm{SD}=4.4)$. No significant differences were found between quiz scores of second- and third-year students for any of the course learning outcomes. From the student evaluations shown in Table 4 and item 5, the student's reported that the quiz questions were representative of the materials and objectives presented in the course noted by the mean score of $4.5(\mathrm{SD}=0.44)$.

On the OSCE activity, 36 out of 36 students achieved $100 \%$ correct responses on six of the nine rubric items. The trans-woman scored 16 of 18 (89\%) students with a correct response on the challenges in their medication therapy question, while the trans-man recorded 18 of 18 $(100 \%)$. Only the two questions on explaining medication adherence (eg, what to do about missed doses) and hormonal dosing schedules had correct answers noted by 30 of $36(83 \%)$ students and 26 of $36(72 \%)$ students, respectively. The OSCE activity was scheduled at the end of the course but prior to the final examinations from the other courses to allow students sufficient time to prepare for it. The trans-man and trans-woman grader also shared their journey of transition with the students. Each student specifically mentioned in their portfolios that this activity increased their self-confidence in speaking with transgender people. This activity also positivity influence scores about half a point (Table 4).

The course faculty evaluated each student's portfolio for completeness on each course topic (Table 1), 10 news items during the semester, assessment of the policy on transgender persons in the military, evaluation of the guest speakers, and self-reflections on each of these. Guest speakers participated in $10 \%$ of the course sessions. The guest speakers provided additional information on their perspectives on treatment barriers (eg, LGBT youth homelessness) and community resources for LGBT persons (eg, The Resources Center Dallas) that were previously unknown to students. The guest speakers invited the students to participate in their program's advocacy activities (eg, city council members) that was also unknown to the students. This information assisted in promoting student learning to the course learning outcomes 5, 6, and 7 . All students evaluated the Trump Administration's policy on transgender persons in the military. From a financial aspect and all other perspectives, the majority concluded that the policy of providing medical services would not be cost prohibitive and may lead to more problems than resolving issues in the military. For example, the military has made policy adjustments reflective of LGBT person's gender identity such as gay men who serve in the U.S. Army Special Forces Green Berets. Common words and themes emerged from the student portfolios such as discrimination, advocacy, inclusive pharmacy environments, and to be a better practitioner. Two students stated that this course assisted them in coming out to their family and friends about their sexual identity, and that many but not all of their family members and friends were supportive of this. Several students shared in their portfolios stated that the course inspired them to begin participating in the LGBT Dallas-Fort Worth community's activities, such as establishing student-led health fairs for the homeless LGBT adult and youth at a local church. Points were deducted from students who failed to include self-reflection or to discuss the required elements in their portfolios.

The faculty supervising each class session had a student roster and noted each time a student participated in the class discussion. These observations took place during topic discussions, journal clubs, case studies, and interactions with guest speakers. Students became more engaged in discussions as the course progressed. Some of the most discussed topics were cultured impressions of persons 


\section{American Journal of Pharmaceutical Education 2019; 83 (8) Article 6967.}

designated as "tomboys," "sissy," and expected societal norms for men and women, and people who were "double" minorities (eg, gay Asian). Every student scored greater than $91 \%$ for participation in the course and students did not display any disrespectful and unprofessional behavior or comments.

A variety of LGBT topics were presented by the students, but the capstone presentation that generated the most questions and discussion was "LGBT in Islam," which was presented by three students of Middle Eastern descent. Each student was originally from a different Middle Eastern country that included Iran, Syria, and Iraq. Several news items included in the presentation were gay men executed for their sexual orientation, placed in jails, and ostracized from their family and society. Family discussions about sexual identities were never mentioned in the Islamic realm, yet, people recognize its existence. Another topic that generated significant discussion was "The Pharmacist's Role in the Transgender Population." Students discussed that the complex medication regimens, drug-drug interactions, and person's journey through transition were key components of the pharmacists' role in working with transgender persons. Creating an inclusive pharmacy environment was a vital component. Students noted that many community pharmacies are without or have limited physical space for consultation rooms.

Faculty members selected two or three students to evaluate each group's presentation using the presentation rubric. Total scores on the presentation were combined and then averaged for each of the 10 items. The average score on the presentations was 46.8 out of a possible 50 points.

Each student was asked to complete a standard UNTHSC course evaluation at the end of the semester, however, only 19 out of the 36 students (53\%) completed one. The mean score on all 11 evaluation questions was 4.5 or greater, indicating most students agreed or strongly agree with all items. The questions and mean score on each are presented in Table 4.

\section{DISCUSSION}

Lesbian, gay, bisexual and transgender persons comprise a significant portion of US society. This group faces numerous challenges to health care access, including barriers to treatment, cultural discrimination, and misperceptions about their sexual identity. The educational curriculum of the medical, pharmacy, and other health care professions include only a small content of their programs that includes LGBT persons. When LGBT health issues are included, these individuals are often grouped together and the unique health needs of each group overlooked. For example, bisexual men and women have sig- nificantly higher alcohol use (more than 14 drinks per week and more than seven drinks per week, respectively) than heterosexual, gay, or lesbian persons. Bisexual men and women also have significantly higher psychological stress than heterosexual, gay, and lesbian persons. ${ }^{29}$ Additionally, an estimated $40 \%$ of homeless youth are LGBT teens and have limited access to health and dental care. These individuals resort to working in the sex industry to survive, which places their health at greater risk. ${ }^{30}$ The guest speaker who was a clergy member that works with LGBT youth mentioned that many are not afraid of being infected with HIV/AIDS as they know that medications are available and that having this medical condition actually increases their access to health care. Pharmacy practice and pharmacy education should continue to evolve to better meet the health care needs of LGBT persons, and one way of accomplishing this is by including LGBT content in the continuing education programs and pharmacy school curriculums. ${ }^{23}$

Pharmacy faculty members at other programs that do not offer a didactic elective course in LGBT health and pharmacy practice may be interested in the course content and assessments described in this article. Ample resources are available including a textbook that can serve as an initial guide for the development of the course. ${ }^{13-15}$ Many health care professional organizations have published guidelines and position papers to incorporate LGBT health care and issues to improve the care of these persons. $^{14,15}$ The course topics and active-learning methods shown in Table 1 are examples that can be modified by other faculty members depending on the health care environment of their institution and student needs.

This elective course used five quizzes mapped to the course learning outcomes displayed in Table 2. The students generally performed well on the quizzes. Mean quiz scores on five of the course learning outcomes were greater than $90 \%$. The course learning outcome 4 had the lowest mean score of $82.2 \%(\mathrm{SD}=6.4)$. This finding was reasonable as most of the class were second-year students who had not yet completed the endocrine module and other courses. However, significant differences in the quiz results between second- and third-year students were not found. The most likely reason for the lower scores was the small number of $\mathrm{P} 3$ students enrolled. The achievement of the Course Learning Outcomes by the students was evident in comparing the Pre-Score versus the Post-Score findings shown in Table 2. The improvement of the percentage of students from the Pre-S.A./A. to the Post-S.A./ A. was highly noted for five of the seven Course Learning Outcomes. The guest speakers were pleasantly surprised that they did not need to define or explain any terms such as gender dysphoria or gender identity for the students. 


\section{American Journal of Pharmaceutical Education 2019; 83 (8) Article 6967.}

The students performed very well on the transgender OSCE with 34 of the 36 students scoring greater than $92 \%$ on seven of nine rubric items. The two item questions had low scores were on hormonal treatment. The course faculty will strengthen the hormonal therapies session in transgender persons with a focus in adherence challenges with missed doses and dosing schedules for the next course offering. These findings can also possibly explain that the lowest Course Learning Outcome item \#4 (Table 2 ). The activity provided the students with an opportunity to speak with a transgender person. The interaction alone was an educational experience as documented in the students' portfolios where each explained they had never met or had a conversation with a transgender person. The faculty members noticed that the students were visibly anxious during the first five minutes of the activity. By the end of the event, both the transgender persons and the students were smiling and laughing. The transgender persons also offered feedback on the OSCE, sharing insights into their varied interactions with pharmacists, as well as how the design and environment of pharmacies had impacted their health care experiences. For example, the transgender persons preferred that a pharmacy have a unisex bathroom.

The student portfolios were extensive and served as a formative assessment that covered a broad range of legal, cultural, medical, and professional insights. ${ }^{26}$ Each student portfolio included comments about how the elective course had taught them many issues they had not previously thought about, including the challenges faced by LGBT individuals. All students were required to assess the Trump Administration's policy on transgender persons serving in the military. The assessment included the policy's impact on military morale and readiness, as well as the costs of medical care for transgender service members. Opposing views presented by the students were included as one of the main issues was medication costs for transgender military personnel. A common theme that emerged from reviewing various student portfolios on this topic where it may be possible that student groups may have worked together to formulate their evaluations. If the students had worked together on this particular assignment, this was an unexpected endeavor and a surprise team-based learning activity.

Students' self-reflections on various news articles included topics from other countries, which surprised the faculty reviewers. The students actively engaged the guest speakers from the local community with very lively question and answer sessions. The most unexpected finding was where two students included statements in their portfolios about how this course had helped them in coming out about their sexual identity to their family and friends. The students were surprised over the support they received from many of their family members and friends.

Most of the students who completed the elective course were second-year pharmacy students. Their knowledge of various pharmacotherapy topics was limited compared to that of third-year students. The endocrine pharmacotherapy course followed by the Cardiovascular module is taught in the spring semester of the second year. When the course was offered in the fall semester, the second-year students had not yet been exposed to the various hormonal therapies. Despite the lack of previous material coverage for the fall semester second year students, these topics were covered during the elective course didactic class sessions with ample reference materials. For the OSCE transgender activity, only four of eighteen student teams scored seven of nine points, which consisted of one team of third year students and three teams of second year students. Two of the three second year student teams were enrolled in the fall semester. The remaining teams scored $100 \%$ on the OSCE activity.

Because students elected to take this course, they were highly motivated to learn and actively participated in the class sessions involving case studies, journal clubs, capstone topic presentations, and other activities. Regrettably, only $53 \%$ of the students completed a course evaluation. The completion rate for all course evaluations by second- and third-year students in fall 2017 was $40 \%$ to $62 \%$. The documented student evaluations were very positive with learning items noted as shown in Table 4 and different results may have occurred if all the students had completed the course evaluations.

This course had limitations. The course fee to support the guest speakers and the OSCE event may have discouraged some students from taking the course. As an elective course, the students who enrolled were highly motivated, which may have influenced their level of participation, performance, and responses on course evaluations. Finally, the elective course was offered in the fall and spring semesters. The student evaluations and comments indicated that the spring semester was better suited to taking the course because the second-year endocrine pharmacotherapy course takes place the previous fall thereby the students having experience with hormonal therapies.

Before this course is implemented in other health professions programs, several factors should be considered. As this is an elective course, the program would need to review the number of elective courses already offered and gauge the interest level of the faculty and students in LGBT issues. Also, the resources we had access to and the availability of LGBT persons and clergy from the local Dallas-Fort Worth community may not be 


\section{American Journal of Pharmaceutical Education 2019; 83 (8) Article 6967.}

similar in other communities. Finally, implementing this course in other programs may also depend on the program's mission and religious and cultural background.

\section{CONCLUSION}

An elective course on LGBT health provided an opportunity for pharmacy student engagement in and exploration of various in-depth topics pertinent to the different and unique health issues faced by members of the LGBT community. After completing the course, students demonstrated an increased knowledge of health resources available to LGBT persons as well as barriers to treatment, and were able to distinguish between the health care needs of different members of the LGBT community. As the number of people in the LGBT community continues to grow, pharmacy programs should consider integrating LGBT health issues into their curriculum. This elective course provides a framework for other pharmacy programs to modify and incorporate into their curriculum.

\section{REFERENCES}

1. Healthy People 2020, Office of Disease Prevention and Health Promotion, US Department of Health and Human Services. Lesbian, gay, bisexual, and transgender health overview. http://www. heathlypeople.gov. LGBT Health. Accessed June 12, 2016. 2. Gates GJ. LGB/T demographics: comparison among populationbased surveys. Williams Institute, UCLA School of Law, 2014. 3. Newfield E, Hart S, Dibble S, Kohler L. Female-to-male transgender quality of life. Qual Life Res. 2006;15(9):1447-1457. 4. Meerwijk EL, Sevelius JM. Transgender population size in the United States: a meta-regression of population-based probability samples. Am J Public Health 2017;107:e1-e8.

5. Gates GJ, Newport F. Special report: $3.4 \%$ of US adults identify as LGBT. Gallup. 18October, 2012. www.gallup.com/poll/158066/ special-reort-adults-identify-lgbt-aspx?version $=$ print. Accessed July 3, 2016 .

6. Gates GJ, Cooke AM. United States Census Snapshot 2010. The Williams Institute, UCLA School of Law. September 2011. http:// williamsinstitute@law.ucla.edu. Accessed July 22, 2016.

7. Obedin-Maliver J, Goldsmith ES, Stewart L, et al. Lesbian, gay, bisexual, and transgender-related content in undergraduate medical education. JAMA. 2011;306(9):971-977.

8. White W, Brenman S, Paradis E, et al. Lesbian, gay, bisexual, and transgender patient care: medical students' preparedness and comfort. Teaching and Learning Med. 2015;27(3):254-263.

9. Seaborne LA, Prince RJ, Kushner DM. Sexual health education in US physician assistant programs. J Sex Med. 2015;12:1158-1164.

10. Khalili J, Leung LB, Diamant AL. Finding the perfect doctor: identifying lesbian, gay, bisexual, and transgender - competent physicians. Am J Public Health. 2015;105(6):1114-1119.

11. Braun HM, Ramirez D, Zahner GJ, Gillis-Buck EM, Sheriff H, Ferrone M. The LGBTQI health forum: an innovative

interprofessional initiative to support curriculum reform. Med Educ Online. 2017;22:1306419. http:dx.doi.org/10.1080/

10872981.2017.1306419.
12. Jann JT, Edmiston EK, Ehrenfield JM. Important considerations for addressing LGBT health care competency. Am J Public Health. 2015;105(11):e8.

13. Makadon HJ, Mayer K, Goldhammer H, Eds. Fenway Guide to Lesbian, Gay, Bisexual and Transgender Health. $2^{\text {nd }}$ Ed. American College of Physicians, Philadelphia, PA 2015.

14. Hollbrach A, Eckstrand K, Dreger. Eds. Instituting Curricular and Institutional Climate Changes to Improve Healthcare for Individuals Who are LGBT, Gender Nonconforming, or Born with DSD. Washington DC. Association of American Medical Colleges; 2014. www.aamc.org. Accessed July 15, 2016.

15. Gay and Lesbian Medical Association Guidelines for Care of Lesbian, Gay, Bisexual and Transgender Patients. 2006.

www.glma.org/publications. Accessed July 15, 2016.

16. Jacobs J. Transgender woman says CVS pharmacist refused to fill hormone prescription. New York Times. July 20, 2018.

17. Accreditation Council for Pharmacy Education. Accreditation Standards and Key Elements for the Professional Program in Pharmacy Leading to the Doctor of Pharmacy Degree. Standards 2016. Chicago, IL. 2015.

18. Wanserski G, Allison A, Anderson P, et al. American Association of Colleges of Pharmacy. Cultural competency: selected resources for instruction, July 2006. https://www.aacp.org/sites/ default/files/2017-11/FinalBibliography.pdf

19. Poirier TI, Butler LM, Devraj R, Gupchup GV, Santanello C, Lynch JC. A cultural competency course for pharmacy students. Am J Pharm Educ. 2009;73(5):Article 81.

20. Ostroff JL, Ostroff ML, Billings S, Nemec II, E. Integration of transgender care into a pharmacy therapeutics curriculum. Curr Pharm Teach Learn 2018;10:463-468.

21. Santee J, Mead T, Garavalia L, Fincham J. Variety and quantity of professional electives. Am J Pharm Educ. 2012;76(10):Article 195.

22. Parkhill AL, Matthews JL, Fearing S, Gainsburg J. A transgender health care panel discussion in a required diversity course. Am J Pharm. Educ 2014; 78 (4):Article 81.

23. Maxwell E, Salch S, Boliko M, Anakwe-Charles G.

Discrepancies in lesbian, gay, bisexual, and transgender patient care and how pharmacists can support an evolved practice. Am J Pharm Educ. 2017;81(7):Article 6181.

24. Gibbs G. Learning by Doing: A Guide to Teaching and Learning Methods. Oxford: Oxford Further Education Unit, 1988.

25. Peeters MJ. Targeting assessment for learning within pharmacy education. Am J Pharm Educ. 2017;81(8):Article 6243.

26. Creswell JW. Qualitative Inquiry and Research Design:

Choosing Among Five Approaches. $3^{\text {rd }}$ ed., Thousand Oaks, CA.

Sage Publications 2013.

27. Sobh AH, Austin Z, Izham MI, Diab MI, Wilby KJ. Application of a systematic approach to evaluating psychometric properties of a cumulative exit-from-degree objective structured clinical examination (OSCE). Curr Pharm Teach Learn 2017;9:1091-1098. 28. De Winter JCF, Dodou D. Five-point Likert items: $t$ test versus Mann-Whitney-Wilcoxon. Practical Assess Res Eval. 2012;15:1-16. 29. Gonzales G, Przedworski J, Henning-Smith C. Comparison of health and health risk factors between lesbian, gay, and bisexual adults and heterosexual adults in the United States. JAMA Intern Med. 2016;176:1344-1351.

30. Seever J, Francis J, Gordon LP, Lee J. Sexual minority youth. Prim Care Clin Office. 2014;41:651-669. 